\title{
Effectiveness of biotechnology on the basis of associative microorganisms at the early stages of forestry process of the Pinus sylvestris $L$.
}

\author{
Marina Yu. Sautkina ${ }^{1 *}$, Nina F. Kuznetsova ${ }^{1}$, Michael A. Semenov ${ }^{1}$ and Andrew S. \\ Khoroschev $^{2}$ \\ ${ }^{1}$ All-Russian Research Institute of Forest Genetics, Breeding and Biotechnology, Department of \\ Forest Genetics and Biotechnology, 394087 Voronezh, Russia \\ ${ }^{2}$ Tambov Regional State Government Institution "Vernadsky forestry", 393976 Tambov Region, \\ Russia
}

\begin{abstract}
The transition to biologically based technologies is one of the priority scientific areas of agriculture and forestry in Russia. The aim of the work is to develop and modify the technology of using biological products on forest tree species and to test it on Scots pine. The effect of pre-sowing inoculation of pine seeds with biological products on soil germination, safety of one- and two-year-old seedlings and their biometric characteristics was studied. The results of the analysis of soil germination of seeds and the safety of 1-year-old seedlings showed that these biological products can be introduced into the technology of growing planting material of Scots pine. It was revealed that the seeds of sensitive trees of the Stupinskaya population turned out to be the most responsive to inoculation with biological products. A stimulating effect has been established on the survival rate of seedlings, preservation, height, growth and diameter of 2-year-old plants in a forestry area (Vernadsky forestry, Tambov region). The height of 2-year-old seedlings of pine 'Ostrogozhskaya' exceeds the control by an average of $18.1 \%$. The use of this biotechnology in forestry production will create favorable conditions for the germination of pine seeds, the growth of seedlings and their higher survival rate.
\end{abstract}

\section{Introduction}

The high rates of climate warming in the Central Black Earth Region impose additional requirements on the species composition, seed and planting material when organizing forestry works in this region. In Russia, the problem of obtaining high-quality planting material in a volume sufficient for forestry production still remains [1]. The high rates of climate warming in the Central Black Earth Region impose additional requirements on the species composition, seed and planting material when organizing forestry works in this region. Measures to improve the sustainability of newly created forests include a set of environmental, technological and biological measures to increase the longevity and

\footnotetext{
*Corresponding author: sautmar@mail.ru
} 
sustainability of forest plantations in more arid conditions (biological soil reclamation, the use of varietal seeds, forms and hybrids of certain forest species) [2].

In recent decades, there has been a deficiency of basic nutrients in the soil. The difficult economic situation with the rather high cost of mineral fertilizers intensifies the need to search for alternative sources of plant nutrition. One of the ways to solve this problem is the use of biological products based on associative microorganisms in the technology of growing planting material $[3,4]$. Plant-microbial interactions are activated under the influence of these biological products. The main mechanisms of the beneficial effect of microorganisms on plants include fixation of molecular nitrogen, optimization of phosphorus nutrition, stimulation of plant growth and development, increase in plant resistance to environmental stress factors, suppression of phytopathogens, etc. In general, the action of associative biological products can be divided into three types: 1) direct stimulation of plant growth and development due to metabolites synthesized by bacteria; 2) an indirect effect due to the displacement of pathogenic microorganisms from the soil microflora; 3) fixation of molecular nitrogen available to plants after bacteria die off [5]. In recent years, a large number of microbial preparations have been created, the effectiveness of which has been proven in many agricultural crops [6-9]. This direction of naturecompatible biotechnology is practically absent in the Russian forest industry. The effectiveness of the influence of associative biological products on forest tree species has been little studied. For reforestation and afforestation of the main forest-forming species, this biotechnology is promising due to its low cost and environmental safety. This was the basis for its development, optimization and testing on Scots pine.

The purpose of research was to study the effect of pre-sowing inoculation of Scots pine seeds with biological products based on associative microorganisms on seed germination, safety of one- and two-year-old seedlings and their biometric characteristics; development and modification of the technology for the use of biological products on forest tree species and testing of its stages on pine seeds of different varietal categories.

\section{Materials and Methods}

In May 2020, in the forest park area of All-Russian Research Institute of Forest Genetics, Breeding and Biotechnology, experience was laid in testing biotechnology based on associative biological products on the seeds of Scots pine of two populations: Stupinsky and pine 'Ostrogozhskaya'. The control population is a typical plantation for the foreststeppe zone, grows in ecologically favourable conditions. The droughty-tolerant variety pine 'Ostrogozhskaya' is located on the southern border of the forest-steppe zone. Earlier we the resistant and drought-sensitive trees were identified in these populations $[10,11]$.

The day before sowing, the seeds went through the process of inoculation with biological products based on associative microorganisms. These preparations were obtained from the All-Russian Institute of Agricultural Microbiology (St. Petersburg). They are registered as fertilizing biological products of complex action of the "ULTRAFIT" group. Each of them is an original biological product with specific mechanisms of interaction with plants. We used: mizorin (strain 7), azorizin (strain 8), strain 17-1, strain 18-5, flavobacterin (strain 30), rhizoagrin (strain 204), strain PG-5, strain 2P-7. Then the inoculated seeds are sown in a prepared soil consisting of ordinary chernozem, sand and peat in a ratio of 1: 1: 1. The experimental scheme for 2020 is described in work [12]. 


\section{Results and Discussion}

Table 1 shows the data of the analysis of the soil germination of the seeds of the harvest of the optimal year of the two studied pine populations.

Table 1. The effect of biological preparations on the germination of Scots pine seeds of different breeding categories

\begin{tabular}{|c|c|c|c|c|}
\hline \multirow{2}{*}{ Experience variant } & \multicolumn{4}{|c|}{ Germination, \% / to control } \\
\cline { 2 - 5 } & $\mathrm{Sr}$ & $\mathrm{Sd}$ & $\mathrm{Or}$ & $\mathrm{Od}$ \\
\hline Control & 65.0 & 29.0 & 40.0 & 49.0 \\
\hline Strain 7 mizorin & $70.0 / 7.7$ & $35.0 / 20.7$ & $44.0 / 10.0$ & $66.0 / 34.7$ \\
\hline Strain 8 azorizin & $62.0 / 0$ & $56.0 / 93.1$ & $37.0 / 0$ & $55.0 / 12.2$ \\
\hline Strain 17-1 & $65.0 / 0$ & $36.0 / 24.1$ & $25.0 / 0$ & $48.0 / 0$ \\
\hline Strain 18-5 & $40.0 / 0$ & $34.0 / 17.2$ & $40.0 / 0$ & $64.0 / 30.6$ \\
\hline Strain 30 flavobacterin & $55.0 / 0$ & $30.0 / 10.3$ & $44.0 / 10.0$ & $83.0 / 69.4$ \\
\hline Strain 204 rhizoagrin & $54.0 / 0$ & $35.0 / 20.7$ & $62.0 / 55.0$ & $49.0 / 0$ \\
\hline Strain PG-5 & $83.0 / 27.7$ & $55.0 / 89.7$ & $48.0 / 20.0$ & $58.0 / 18.4$ \\
\hline Strain 2P-7 & $73.0 / 12.3$ & $37.0 / 27.6$ & $59.0 / 47.5$ & $59.0 / 20.4$ \\
\hline
\end{tabular}

Note: Seeds of resistant $(\mathrm{Sr})$ and drought-sensitive $(\mathrm{Sd})$ trees of the Stypinskaya population; resistant (Or) and drought-sensitive (Od) trees of pine 'Ostrogozhskaya'.

It was shown that the most responsive to inoculation with biological products were the seeds of sensitive trees of the Stypinskaya population (Table 1). In all variants of the experiment, an increase in indicators of soil germination relative to control was noted. The maximum stimulating effect is shown in variants with azorizin (strain 8) and strain PG-5, where the number of seedlings was almost twice as high as the control: +93.1 and $89.7 \%$, respectively (Table 1). Also, a pronounced effect from the use of biological products was noted on the seeds of sensitive trees of the varietal population. It has been shown that the maximum stimulating effect on increasing soil germination was revealed when seeds were inoculated with flavobacterin (strain 30) - 69.4\%. Inoculation of seeds of resistant pine trees with pine 'Ostrogozhskaya' with rhizoagrin (strain 204) made it possible to increase soil germination by $55 \%$ relative to control.

In the third decade of August, the safety 1-year-old pine seedlings of control and experimental variants was determined (Figures 1,2 ).

In almost all variants of the experiment, high rates of seedling safety were noted. In general, it was revealed that the highest safety is in the offspring of sensitive trees of the Stupa population. The maximum result was found in the variant with azorizine (pcs. 8): the preservation was $89.3 \%$. In other variants of inoculation of seeds of this population, the safety ranged from 66.7 (strain 17-1) to $86.7 \%$ (strain 30 flavobacterin).

The high preservation of the seedlings of the 'Ostrogozhskaya' pine was noted. Thus, the maximum preservation rates were observed in seedlings of sensitive trees in variants with strain 204 (rhizoagrin) and 17-1 - 83.7 and 81.3\%, respectively (Figure 2). For resistant trees of this population, a high preservation was also revealed in variants with strains 17-1, 30 (flavobacterin) and PG-5 - 80.0, 79.5 and 79.5\%, respectively (Figure 2).

In autumn, seedlings of resistant trees of the experimental and control populations were planted on a forest-cultural area in the Vernadsky Forestry of the Tambov region. In May 2021, measurements of the biometric characteristics of pine seedlings were made and their safety was determined. 


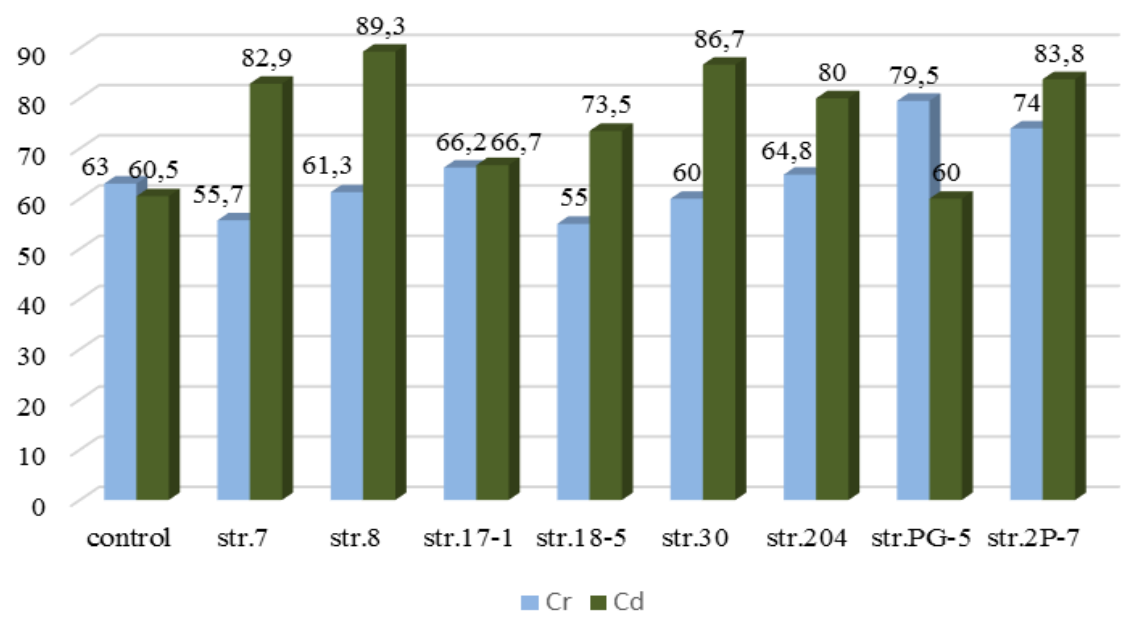

Fig. 1. Influence of biological products based on associative microorganisms on the safety of Scots pine seedlings, Stupinskaya population, $\%$

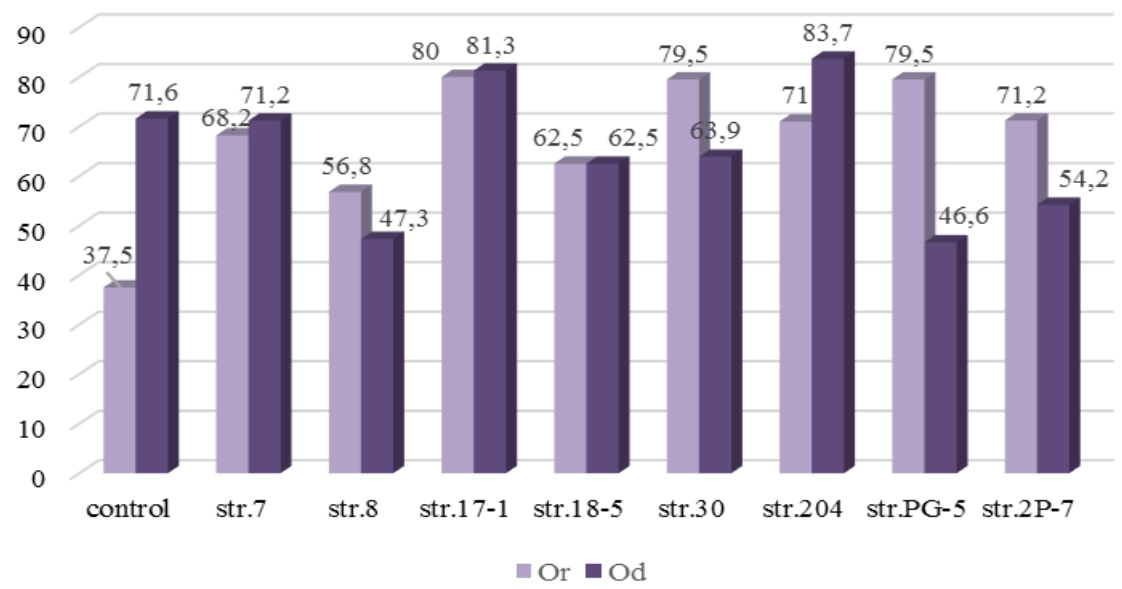

Fig.2. Influence of biological products based on associative microorganisms on the safety of Scots pine seedlings of the varietal pine 'Ostrogozhskaya', \%

The results of the analysis of biometric characteristics of control (untreated with biological products) variants of the field experiment showed that the height of seedlings of the pine 'Ostrogozhskaya' is $18.1 \%$ higher than that of seedlings of the Stupinsky population (Table 2).

It was found that inoculation with associative biological products had a stimulating effect on the growth of seedlings of the Stupinsky population in all treatment options, except for str. 17-1. The maximum plant heights are noted in the variant with str. 204 (rhizoagrin) $-6.47 \pm 0.42 \mathrm{~cm}$, which is $37.1 \%$ higher than the control (Table 2). Also, a significant increase in height was noted in variants with str. $18-5$ and $2 \mathrm{P}-7$ - by 30.3 and $20.8 \%$, respectively. In other variants, the increase in the height of seedlings relative to the control ranged from $15.2 \%$ (str. PG-5) to $24.1 \%$ (str. 30 flavobacterin). For seedlings of pine 'Ostrogozhskaya', a positive effect of biological products on plant height was also noted. So, the maximum result was shown by azorizin (str. 8 ) $-6.65 \pm 0.40 \mathrm{~cm}$, which is $33.8 \%$ higher than the control (table 2). The stimulating effect after inoculation with strains 7 (mizorin) and $18-5$ was 7.2 and $13.5 \%$, respectively. 
Table 2. Biometric indicators of 2-year-old seedlings of scots pine on the forest area (measurement date 21.05.2021)

\begin{tabular}{|l|c|c|c|}
\hline \multicolumn{1}{|c|}{ Experience variant } & Height, cm & Diameter, $\mathrm{mm}$ & Growth, cm \\
\hline Sr control & $4.07 \pm 0.32$ & $0.93 \pm 0.02$ & $0.80 \pm 0.01$ \\
\hline Sr+str.7(mizorin) & $4.91 \pm 0.28$ & $1.01 \pm 0.02$ & $1.18 \pm 0.08$ \\
\hline Sr+str.8(azorizin) & $4.79 \pm 0.37$ & $0.99 \pm 0.04$ & $1.56 \pm 0.14$ \\
\hline Sr+ str.17-1 & $3.84 \pm 0.35$ & $1.05 \pm 0.03$ & $1.24 \pm 0.20$ \\
\hline Sr+str.18-5 & $5.84 \pm 0.43$ & $0.99 \pm 0.01$ & $1.33 \pm 0.16$ \\
\hline Sr+str.30(flavobacterin) & $5.05 \pm 0.37$ & $0.95 \pm 0.02$ & $1.35 \pm 0.23$ \\
\hline Sr+str.204(rhizoagrin) & $6.47 \pm 0.42$ & $1.07 \pm 0.01$ & $1.95 \pm 0.23$ \\
\hline Sr+str.PG-5 & $4.69 \pm 0.22$ & $0.98 \pm 0.03$ & $1.51 \pm 0.13$ \\
\hline Sr+str.2P-7 & $5.14 \pm 0.27$ & $0.98 \pm 0.02$ & $1.70 \pm 0.15$ \\
\hline Or control & $4.97 \pm 0.22$ & $1.01 \pm 0.02$ & $1.39 \pm 0.13$ \\
\hline Or+str.7(mizorin) & $5.33 \pm 0.38$ & $1.00 \pm 0.03$ & $1.61 \pm 0.17$ \\
\hline Or+str.8(azorizin) & $6.65 \pm 0.40$ & $1.21 \pm 0.08$ & $1.99 \pm 0.18$ \\
\hline Or+str.18-5 & $5.64 \pm 0.27$ & $1.24 \pm 0.08$ & $1.98 \pm 0.19$ \\
\hline
\end{tabular}

The average diameter of plants at the root collar in the experimental variants of the Stupinsky population exceeds the control from 5.4\% (str. PG-5, 2P-7) to $15.1 \%$ (str. 204 rhizoagrin). In the seedlings of pine 'Ostrogozhskaya', the excess of this parameter is in variants with str. 8 (azorizin) and $18-5$ by 19.8 and $22.8 \%$, respectively (Table 2).

The effectiveness of the biological products used can be judged by the size of the annual growth of seedlings in the first year after their transplantation to forestry area (Table 2,3).

Table 3. The influence of biological products based on associative microorganisms on the safety of 2 year-old Scots pine seedlings

\begin{tabular}{|l|c|}
\hline \multicolumn{1}{|c|}{ Experience variant } & Safety, \% \\
\hline Sr control & 66.7 \\
\hline Sr+str.7(mizorin) & 88.9 \\
\hline Sr+str.8(azorizin) & 73.3 \\
\hline Sr+ str.17-1 & 44.4 \\
\hline Sr+str.18-5 & 100 \\
\hline Sr+str.30(flavobacterin) & 76.5 \\
\hline Sr+str.204(rhizoagrin) & 100 \\
\hline Sr+str.PG-5 & 80.6 \\
\hline Sr+str.2P-7 & 67.6 \\
\hline Or control & 85.7 \\
\hline Or+str.7(mizorin) & 70.6 \\
\hline Or+str.8(azorizin) & 66.7 \\
\hline Or+str.18-5 & 90.9 \\
\hline
\end{tabular}

The maximum stimulating effect is shown when processing str. 204 (rhizoagrin). The growth of seedlings is $1.95 \pm 0.23 \mathrm{~cm}$, which is 2.4 times higher than the control $(0.80 \pm$ $0.01 \mathrm{~cm}$ ). A significant increase in growth was noted in variants with str.2P-7, 8 (azorizin) and PG-5 - by 112.5 ; 95 and $88.8 \%$, respectively (Table 2). The greatest result of varietal seedlings was obtained in variants with str. 8 (azorizin) and 18-5 - $1.99 \pm 0.18$ and $1.98 \pm$ $0.19 \mathrm{~cm}$, respectively, which is higher than the control by 23.6 and $23.0 \%$. In general, it should be noted that the growth of seedlings in the experimental version of the pine 'Ostrogozhskaya' is $73.8 \%$ higher than in the Stupinsky population. At the end of May, the safety of seedlings was taken into account. Compared with the control, the safety of varietal seedlings is $19 \%$ higher. $100 \%$ survival of plants of the Stupinsky population was noted in variants with str. 18-5 and 204 (rhizoagrin) (Table 3). In other variants of seed treatment of the Stupinsky population, the safety of seedlings was $67.6 \%$ (str. $2 \mathrm{P}-7$ ) $-88.9 \%$ (str.7 
mizorin). Of the seedlings of the pine 'Ostrogozhskaya' planted on the forestry area, the plants in the variant with str. 18-5 had the greatest preservation $-90.9 \%$ (Table 3).

\section{Conclusion}

Thus, the two-year results obtained on the approbation and study of the effect of biological products based on associative microorganisms on the quality of 1- and 2-year-old Scots pine seedlings confirm the expediency of their use in the forestry of the Russian Federation. The use of these biological products is cost-effective, environmentally friendly and contributes to the production of high-quality planting material. This biotechnology is environmentally compatible, as it imitates real natural processes. It can be introduced into the technology of forestry production at the stage of obtaining planting material, will create favorable conditions for seed germination and seedling growth, as well as increase the yield of standard planting material per unit area.

\section{References}

1. T.S. Ustinova, Act. Prob. of the For. Compl. 23 (2009)

2. S.N. Kryuchkov, A.S. Stolnov, Sc.-agr. J. 103, 2 (2018)

3. M.Yu. Sautkina, Yu. I. Cheverdin, 6th International Conference on Agriproducts processing and Farming, Voronezh (2020)

4. A. Yu. Cheverdin, M.Yu. Sautkina, Yu. I. Cheverdin, $9^{\text {th }}$ International Symposium «Steppes of Northern Eurasia», Orenburg (2021)

5. I.A. Tikhonovich, A.A. Zavalin, G. G. Blagoveshchenskaya, A.P. Kozhemyakov, Plod.J. 3 (2011)

6. E.A. Blinkov, Actual aspects of modern microbiology: collection of articles scientific. tr., Moscow (2010)

7. A.A. Belimov, N.Yu. Zinovkina, A.I. Shaposhnikov, et al, Methods for assessing agricultural risks and technologies for mitigating the effects of climate change in agriculture: collection of articles scientific. tr., St.Petersburg (2011)

8. A.A. Zavalin, N. S. Almetov, The use of biological products and biological nitrogen in agriculture in the Non-Black Earth Region (2009)

9. A.P. Kozhemyakov, S.V. Timofeeva, Agr. Exp.J. 2 (2007)

10. N. F. Kuznetsova, Izv. Saratov Univ. (N. S.), Ser. Earth Sc. 19, 3 (2019)

11. E.S. Klushevskaya, N.F. Kuznetsova, Rast. Res. 55, 3 (2019)

12. M.Yu. Sautkina, N.F. Kuznetsova, Bull. of MichGAU 65, 2 (2021) 